\title{
The Efficacy of Cognitive Behavioral Intervention to Reduce Symptoms of Anxiety Disorder with an Adult in Bangladesh: A Clinical Case study
}

Jesan Ara*

Department of Psychology, University of Rajshahi, Bangladesh

Submission: June 13, 2020; Published: November 13, 2020

*Corresponding author: Jesan Ara, Department of Psychology, University of Rajshahi, Rajshahi, Bangladesh

\begin{abstract}
Anxiety disorder is one of the most common mental health problems are characterized by perception of danger, thoughts about harm, a process of physiological alarm and activation, typically in response to a specified object or situation and in the absence of true danger. The case is going to present concerns of a 38-year-old unmarried male client, suffering from anxiety disorder. He sought help for suicidal ideation, withdrawal from social gatherings and lower level of activity. This article is based on the application of Cognitive Behavioral Intervention which provided the basic necessary tools for active involvement on changing negative automatic thoughts, cognitive distortion and behaviors whose impact was reflected in the decline in symptoms of anxiety, increasing self-confidence, reduce suicidal ideation and higher level of activity. This case study demonstrated that Cognitive Behavior Therapy is effective in reducing symptoms of anxiety. Moreover, the findings of this study will help the professionals working in mental health field to reduce the knowledge gap and help them to make better treatment modification.
\end{abstract}

Keywords: Cognitive Behavior Therapy; Anxiety disorder; Mental health professional; Cognitive distortion.

\section{Introduction}

Anxiety disorders are characterized by perception of danger, thoughts about harm, a process of physiological alarm and activation, typically in response to a specified object or situation and in the absence of true danger [1]. Anxiety disorders have the highest overall prevalence rate among psychiatric disorders, with 12 -month and lifetime rates of $17 \%$ and $28.8 \%$, respectively $[2,3]$. Cognitive behavioral therapy (CBT) has been shown to be effective for a wide variety of mental health disorders, including anxiety disorders $[4,5]$. Cognitive Behavior Therapy has evolved from a specific treatment model into a scientific approach that incorporates a wide variety of disorder-specific interventions and treatment techniques [6]. The origin of CBT goes back to the 1960s which was developed by Aaron Beck, since then it has been studied extensively and expanded [7]. From the primary focus on depression, CBT has been extended to treat a wide range of disorders. CBT for anxiety is aimed at symptoms reduction, through the identification and modification of negative automatic thought and cognitive distortions [8]. Essential components of CBT include focus on helping clients solve problems; become behaviorally activated; and identify, evaluate, and respond to their distorted thinking, especially to negative thinking about themselves, their worlds, and their future [9]. International evidence suggests that CBT is cost-effective and it has long term effectiveness [10]. CBT has undergone extensive scientific examination through comparisons in RCTs, element analyses, and mediation analyses for anxiety disorder [8].

\section{Case Description}

Mr. X, a 38-year-old unmarried male Muslim client was referred to the clinical psychologist for psychological intervention by the psychiatry outpatient department. He was diagnosed as having anxiety disorder by the referring agency. In the assessment sessions he presented his problems along with history. Although he sought help for suicidal ideation, withdrawal from social 
gatherings and lower level of activity but through the assessment procedure problems in other areas of functioning were revealed. The client believed that he was suffering from psychological and physical illness. The client complained lack of concentration, lack of self-confidence, poor memory, and indecisiveness. The client also complained of tensed and depressed mood, feeling of guilt, lack of pleasure, loneliness, anger, hopelessness and worthlessness. He also felt irritability, fear and feeling of discomfort. He avoids social gathering, friends and can't cope with stress. The client complained of headache, palpitation, dryness of throat, loss of appetite and sleep disturbance. The client complained that family members irritated him, disrupted family relationship and disrupted social interaction. The client's dress up, appearance and behavior appeared to be culturally appropriate. As he came alone for psychotherapy sessions, it was not possible to check the information from relevant others. But it can be believed that most of the information that was collected from the client was reliable as the client came for treatment with his own interest.

\section{Personal and family history}

Mr. X brought up in the urban area in a family of upper middle socio-economic status with two sisters. His father is 75 years old retired Govt. employee. His mother is a 68 years old house wife. According to the client his father is very dominating and always used to criticize him; he usually didn't praise the client even after completion of good work. But the client had a good understanding with his mother. The client had not been in good terms with the eldest sister. The reason behind is that she is so much the same as her father. She was always in a spot of bother because his brotherin-low (husband of eldest sister) was an addicted person. The immediate senior sister close to his age is aged 40 years; both he and his sister are still single. But his parents did not give attention for solving this issue. Under the state of these affairs there was and is always prevailing disrupted relationship between the members of the family.

The client's birth history was normal. His father and sisters did lot of criticism to the client during childhood. In childhood, the client's performance was good in school, but he did not want to mix with others. In 1996 his family suffered from a car accident. None was injured, but police arrested their driver. From that time on he was afraid of hearing the death news of any human being till 2000. At the age of 19 years, in 2000 he was caught by acute fever and vomiting. As a result, he wasn't able to seat for the H.S.C exam. He was on bed for 3 years continuously and appeared in the H.S.C exam in 2004 but didn't obtain expected outcome. In 2006 he suffered from Nephritis. After coming round from that he got a tendency of vomiting. There was no history of psychiatric problem in childhood and adolescence. In the year of 2010 at the time of doing his bachelor's degree he got affair with a married lady. As a result, most of his friends started to criticize him. There also grew a big gap with his friends. Every day he talked with the lady by phone for 10-11 hours and for this close involvement with the lady he was a bit relieved from his struggle of family. But in June 2017 their relationship had broken down. Then he did not take part on L.L.B examination (part-2) in 2017. For all this now he is not interested to start his profession related to his academic background. Considering this in combination with the disrupted family environment and suddenly relationship breakup with loved one it comes as no wonder that Mr. X developed an anxiety disorder.

\section{Assessment}

In clinical interview the Mr. $\mathrm{X}$ was asked the reason for referral, why he sought for help and how long the main complaint had persisted, when did the problem first occur and how did he and others react to it, what was the subsequent development in his life (occupation, living with parents, at school), what were the impairments that had been produced by his difficulties, how had he and others coped with the problem, what was his belief about the problem, what was the attitude to his difficulties, what was his cognitive functioning, what was his prevailing mood, what was his background history, early development history, occupational and educational history, sexual history and what previous psychiatric, psychological or medical help he had taken. The client was asked to find out and list up his main problems. Thought diary was applied to assess situation specific NAT's and corresponding emotion, physiological changes and behavior for the client. The client had negative thought about social situation. It was administered to identify the NAT's about the social situation and the relation to changes in emotion, physical reaction, and behavior. He also asked what he thought will happen at times when he was in greatest distress. Therapist conducted both type of measurement, subjective \& objective measurement. In 'subjective measurement' the client mentioned his overall problems severity at ' 100 ' point on (0-100) rating scale. In 'objective measurement' Depression scale [11] was used to assess the severity of depression. And Anxiety scale [12] was administrated to assess the severity level of anxiety from the very begging sessions. From the $4^{\text {th }}$ session Social Interaction Anxiety [13] scale was also used to assess client's social anxiety level. Scores of these scales in assessment phase is presented in Table 1.

\section{Formulation}

A 38-year-old unmarried male Muslim client was referred to the clinical psychologist for psychological intervention by the psychiatry outpatient department. On the basis of information's collected from the client, his formulation was done in predisposing, precipitating \& maintaining factors. The PPM formulation is given below-

\section{Predisposing factors}

According to the client his father is very dominating and always used criticize his son; even after completion of good work 
and he usually did not praise the client. From these, the clients negative appraisal about own self was developed. In general, the particular appraisal made will depend on the context in which an event occurs, the mood the person is in at the time it occurs, and the person's past experiences [14\}. He has not been in good terms with the eldest sister and she also always used to criticize him. In general, behavioral models claim that depressive mood comes about because the person is receiving inadequate or insufficient positive reinforcement or reward from his or her environment [15].

Table 1: Anxiety, depression and social interaction scores.

\begin{tabular}{|c|c|c|}
\hline Scale & $\mathbf{1}^{\text {st }}$ Session & $\mathbf{4}^{\text {th }}$ Session \\
\hline Depression Scale & (20 (Moderate) & - \\
\hline Anxiety Scale & 78 (profound) & - \\
\hline Social interaction scale & - & 41 (Very much) \\
\hline
\end{tabular}

He was always in a spot of bother because his brother-inlow (husband of eldest sister) was an addicted person and he was afraid for that. In 1996 his family suffered a car accident. From that time on he was afraid of hearing the death news of any human being till 2000. All these situations lead to fear about unexpected situation and his anxiety was developed. In anxiety disorder the disturbance in information processing which underlies anxiety vulnerability and anxiety maintenance can be viewed as a preoccupation with or 'fixation' on the concept of danger, and associated underestimation of personal ability to cope [16]. At the age of 19 years, in 2000 he was caught by an acute fever and vomiting. As a result, he was not able to sit for the H.S.C exam. He was on bed for 3 years continuously and appeared in the H.S.C exam in 2004 but did not obtain expected outcome. All these factors made the client vulnerable from psychiatric problem.

\section{Precipitating factors}

In the year of 2010 at the time of doing his bachelor's degree he got affair with a married lady. In June 2017 their relationship was broken down. Then developed his current problem (symptoms mentioned in problem description).

\section{Maintaining Factors}

Mr. X's family environment was not warm. His father was very dominating and always used to him. Relationship with sibling was not friendly, so he couldn't share his feelings with them. The client also didn't have close friends. He was passive in habit, he couldn't express his emotion or opinion, which make him more anxious \& depressed and it maintain his problems. He felt that he became as a negative example for all other person. For all of these reasons he was anxious to face any situation where he might be evaluated. The client used to avoid social situations and friend. This avoidance also acting as a maintaining factor for his current illness. The client was professionally unsuccessful and could not earn much. It was also acting as a maintaining factor. The client had some negative thought about own self, such as-"I'm inadequate", "I have no ability to do any good things", "I can't do anything in my life", "I have no professionalism". All these belief lead to indecisiveness, lack of self-confidence and maintain his problem (Flow chart).

The client also had some symptoms which helped to maintain his problems, such as- tensed and depressed mood, feeling of guilt, lack of pleasure, loneliness, anger, irritability, fear, hopelessness and worthlessness. Avoid social gathering and lower level of activity, headache, loss of appetite, sleep disturbance, palpitation, and dryness of throat. All these symptoms also acting as a maintaining factor for his current illness. After obtaining information on predisposing, precipitating and maintaining factors, client's problem is also shown in following cognitive model described by Beck [14].

\section{Intervention}

The formulation of the client's problem was drawn on the basis of cognitive model and cognitive behavior therapy was chosen for the clients problem. Clinical Psychologist had conducted 12 sessions for this client (three assessment sessions and one followup session). Formulation was shared with the client to make him understand his own problems. It also prepared the client to follow treatment regime. Goals of the treatment were set and defined collaboratively with Mr. X, such as: coping with stressful situation, reduction of avoidance and reduction of symptoms. Priorities were then set by negotiating the client to which problems were to be dealt with first. Cognitive behavior therapy is a form of psychotherapy; the process of treatment includes raising the awareness of the patients' thoughts, feeling and emotion. Patients are taught how to recognize their own automatic thoughts and how to substitute them with more constructive and less anxiety provoking ways of viewing their outside world. 

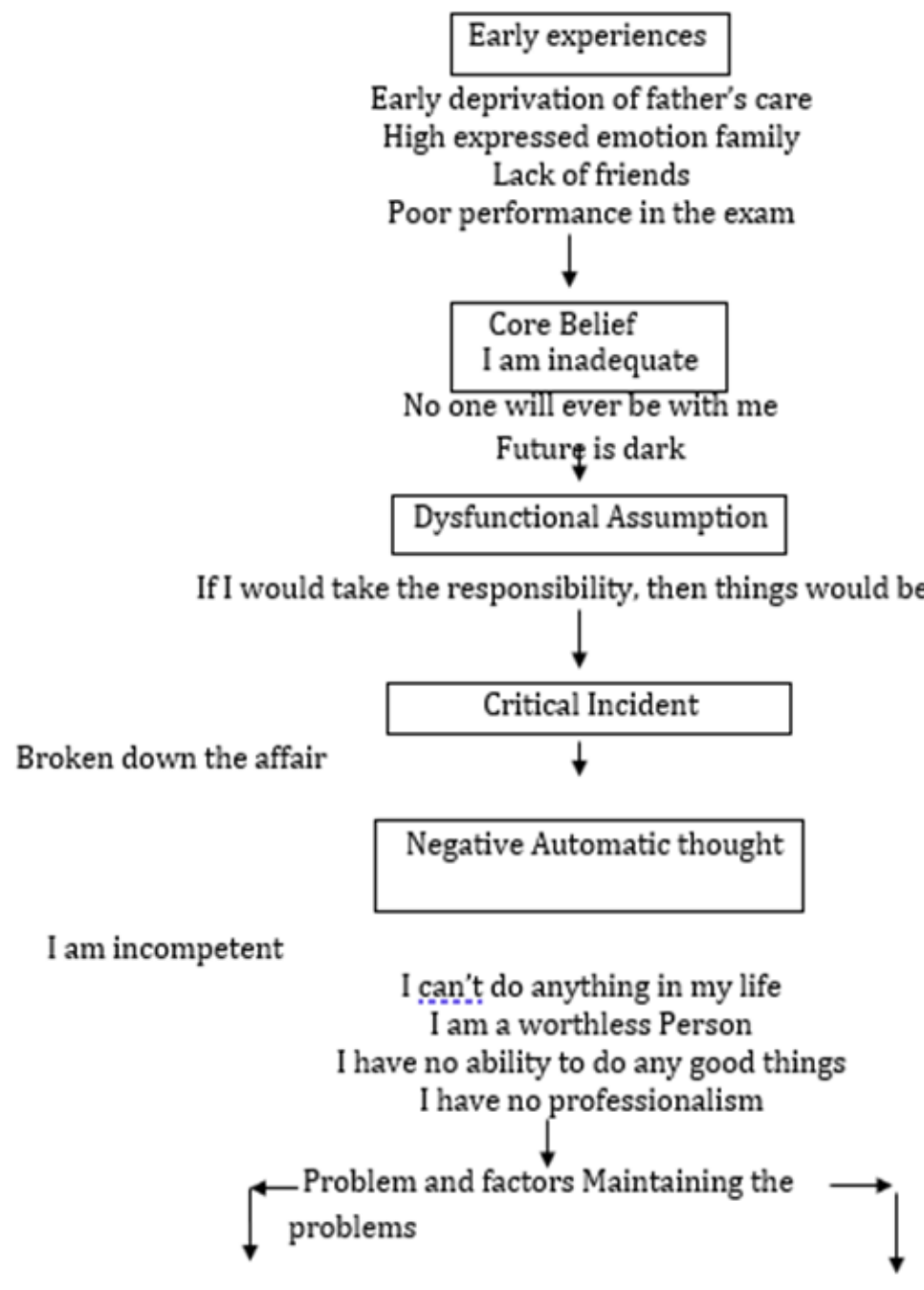

COGNITIVE : Indecisiveness, lack of concentration, lack of self-confidence, poor memory.

EMOTIONAL: Tensed and depressed mood, feeling of guilt, lack of pleasure, loneliness, anger, hopelessness and worthlessness, irritability, fear.

BEHAVIORAL: Avoid social gathering, friends and lower level of activity. PHYSIOLOGICAL: Headache, loss of appetite, sleep disturbance, palpitation, dryness of throat.

ENVIRONMENTAL: Irritated from family members, disrupted family

Flow chart: Maintaining factor.

Following cognitive-behavior therapeutic techniques were followed in the sessions:

i. The client was not assertive and could not express his feelings appropriately. In therapy session sufficient rapport was established and he expressed his thoughts, feelings, behavior and so on. For this reason, he felt better than before. Therapist also used 'monitoring activities', the client complained lack of pleasure and lower level of activity. So, a record-sheet was given to client to record what he did on an hour-by-hour basis, and to rate each activity out of 10 for pleasure predicting (P) and for mastery (M). It was used in order to improve mood and to increase level of activities. 
ii. Muscular relaxation was taught to reduce headache and anxiety symptoms. Evidence suggests that relaxation procedure have been effective for a vast array of problems including headache, insomnia, anxiety and temper outburst [17].

Though challenge was used to modify the client's negative automatic thoughts by examining the evidence for against the NAT's of the client. Cognitive behavior therapy was given to reduce his NAT's, as NAT's maintaining his problems. The client often underestimated his 'positive qualities' which maintained his problems. So the client was asked to write down least two good qualities every day. So that he could be aware about his positive qualities, it would help him to perceive himself in another perspective. In treatment process pros and con's technique was used. Here, the client was asked to list out the advantages and disadvantages to modify the client's NAT's. If any bad incident happened, the client felt responsibility for that and also felt guilt. Here 'pie' technique helped the client to determine his responsibility for an incident. This technique was given to reduce his guilt feelings as it maintains his problem. The client was also avoiding hard work and any social situation. 'Exposure techniques' was used in order to terminate this avoidance as these were maintaining his current problems. The client was taught how to express anger in a constructive way, so 'anger control' technique was used. These include defining what the anger is about, being assertive and finding some mutual way of solving the problem. The client had some social skill deficits which were maintaining his problems. So the client was referred to 'social skill training
(SST)' at the medical institute to learn social skill.

\section{Results}

Subjective rating of the client's problem was taken intermittently in assessment and treatment session. Standardized scale was applied in most of the session to get an objective measure of the improvement and also to provide an objective feedback about improvement to the client and therapist. Anxiety, depression and social interaction anxiety scale were used as objective measures of improvement. Session wise scores of these scales are presented in Table 3. The subjective and objective report of the result of intervention strongly suggests that improvement have occurred. Graphical representation of anxiety, depression and social interaction anxiety scale scores is presented in Figure 1. Despite the difficulties in treatment (non-co-operative family members and only one follow-up session) the client showed consistent improvement. He followed all tasks. He was well motivated and showed high level of compliance with CBT. He accepted psychotherapeutic formulation for his problems, and he could internalize therapeutic techniques and it's rational. After intervention, his physical symptoms were reduced. He started to attend social gatherings and friends. He pursued his LLB studies again. His NAT's were reduced, and he started thinking positively. He could generalize psychotherapy. It can indicate that CBT is effective for Mr. X and he applied acquired skill in different settings. Such generalization was a good indication of his prognosis.

Table 2: Subjective report of the client in treatment session.

\begin{tabular}{|l|c|c|c|c|}
\hline & Initial session & $\mathbf{4}^{\text {th }}$ session & $\mathbf{7}^{\text {th }}$ session & $\mathbf{1 2}^{\text {th }}$ session \\
\hline Overall problem rating(0-100) & 100 & 60 & 40 & 10 \\
\hline
\end{tabular}

Table 3: Anxiety, depression and social interaction scores through the session.

\begin{tabular}{|c|c|c|c|}
\hline \multirow{2}{*}{ No of session } & Anxiety scale & Depression scale & Social interaction anxiety scale \\
\hline $1^{\text {st }}$ & 78 ( Profound) & 120 (Moderate) & 41 (Very much) \\
\hline $4^{\text {th }}$ & 62 (Moderate) & 106 (Mild) & 25 (Moderately) \\
\hline $6^{\text {th }}$ & 58 (Moderate) & 104 (Mild) & 18 (Slightly) \\
\hline $7^{\text {th }}$ & 52 (Mild) & 93 (Below cut off point) & 16 ( Slightly) \\
\hline $9^{\text {th }}$ & 45 (Below cut off point) & 70 (Below cut off point) & 12 (Slightly) \\
\hline $10^{\text {th }}$ & 39 (Below cut off point) & 65 (Below cut off point) & 62 (Below cut off point) \\
\hline $12^{\text {th }}\left(1^{\text {st }}\right.$ follow-up session) & 32 (Below cut off point) & & \\
\hline
\end{tabular}




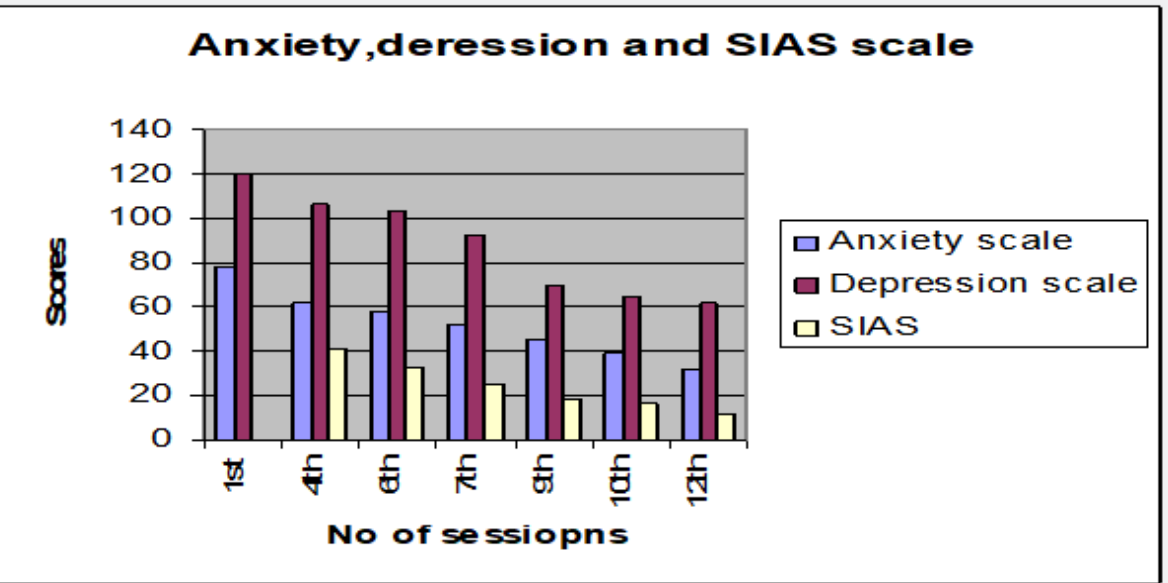

Figure1: Graphical representation of Anxiety, depression and SIAS scores.

\section{Critical Discussion}

Though the client was diagnosed as anxiety disorder but most of the symptoms were related to symptoms of depression. In therapy sessions the client expressed his feelings, thoughts and behavior. By ventilate his feelings he felt much better and improvement had occurred. The client was motivated for change and it seems that there would be less probability of relapsing. For the client's better outcome family therapy was needed. It would be helpful for the client if conducting a joint session with his parents and siblings. But it was not possible for non-co-operation from family members.

\section{References}

1. Otte C (2011) Cognitive behavioral therapy in anxiety disorders: current state of the evidence. Dialogues in clinical neuroscience 13(4): 413.

2. Kessler RC, Demler O, Frank RG, Olfson M, Pincus HA., et al. (2005) Prevalence and treatment of mental disorders, 1990 to 2003. New England Journal of Medicine 352(24): 2515-2523.

3. Nath S, Ryan EG, Trevillion K, Bick D, Demilew J, et al. (2018) Prevalence and identification of anxiety disorders in pregnancy: the diagnostic accuracy of the two-item Generalised Anxiety Disorder scale (GAD-2). BMJ open 8(9).

4. Chambless DL, Ollendick TH (2001) Empirically supported psychological interventions: Controversies and evidence. Annual review of psychology 52(1): 685-716.

5. Hans E, Hiller W (2013) A meta-analysis of nonrandomized effectiveness studies on outpatient cognitive behavioral therapy for adult anxiety disorders. Clinical psychology review 33(8): 954-964.
6. Hofmann SG, Asmundson GJ, Beck AT (2013) The science of cognitive therapy. Behavior therapy 44(2): 199-212.

7. Grant A, Townend M, Mulhern R, Short N (2010) Cognitive behavioural therapy in mental health care. Sage, United States.

8. Hofmann SG, Smits JA (2008) Cognitive-behavioral therapy for adult anxiety disorders: a meta-analysis of randomized placebo-controlled trials. The Journal of clinical psychiatry 69(4): 621.

9. Beck JS, Beck AT (2011) Cognitive behavior therapy: basics and beyond, vol. 391. (2 ${ }^{\text {nd }}$ Edtn.) Guilford Press, New York, United Sates.

10. Hollinghurst S, Peters TJ, Kaur S, Wiles N, Lewisand G, et al. (2010) Cost-effectiveness of therapist-delivered online cognitive-behavioural therapy for depression: randomised controlled trial. The British Journal of Psychiatry 197(4): 297-304.

11. Uddin MZ, Rahman MM (2005) Development of A Scale of Depression for use in Bangladesh. Bangladesh Psychological Studies 15: 25-44.

12. Deeba F, Begum R (2004) Development of an Anxiety Scale for Bangladeshi Population. Bangladesh Psychological Studies 14: 39-54.

13. Mattick RP, Clarke JC (1998) Development and validation of measures of social phobia scrutiny fear and social interaction anxiety. Behaviour research and therapy 36(4): 455-470.

14. Beck AT (1976) Cognitive therapy and the emotional disorders. W H, New York, United States.

15. Champion L, Power M (2014) Adult psychological problems: an introduction. Taylor \& Francis, United Kingdom.

16. Beck AT, Emery G, Greenberg RL (2005) Anxiety disorders and phobias: A cognitive perspective. Basic Books.

17. Harvey JR, Karan OC, Bhargava D, Morehouse N (1978) Relaxation training and cognitive behavioral procedures to reduce violent temper outbursts in a moderately retarded woman. Journal of Behavior Therapy and Experimental Psychiatry 9(4): 347-351. 
Your next submission with Juniper Publishers will reach you the below assets

- Quality Editorial service

- Swift Peer Review

- Reprints availability

- E-prints Service

- Manuscript Podcast for convenient understanding

- Global attainment for your research

- Manuscript accessibility in different formats ( Pdf, E-pub, Full Text, Audio)

- Unceasing customer service

Track the below URL for one-step submission https://juniperpublishers.com/online-submission.php 